\title{
FREIGHT CENTERS \\ FUTURE NODES OF AN EUROPEAN LOGISTICS NETWORK
}

\author{
Dietrich Fischer, GARONOR Planungs- und Betriebs-GmbH, Taufkirchen
}

The heavy increase in transport, distribution and production logistics during the last decades has along with the growing competition in the logistics market - resulted in a new concept, that is expected to increase the efficiency of the European logistics system and reduce the environmental impacts at the same time, i. e. freight centers rsp. logistic platforms, in German: Güterverkehrszentren.

These freight centers covering from 50 to 200 ha and offering 2000 - 5000 jobs are supposed to offer at least interfaces between road and rail transportation, in the ideal case also between water and air. Within the center - as part of their infra- rsp. suprastructure - they are supposed to provide all types of service of interest to a logistics company, including any meachanism to foster a voluntary cooperation between the various companies settled in the same center or in various centers to reduce long and short distance (city logistics) transportation by increasing average load factors and sharing overhead costs.

In Western Europe îreight centers have developed over the last three decades, mainly as part of the GARONOR chain. In 1990 an European Organisation called EUROPLATFORM was established to ease an international exchange of experience and foster a linkage of the freight centers to a working European network.

In Germany official policy even claims combined traffic terminals incl. freight nodes conceived by the federal railway and the postal system to become an intergral part of freight centers specified in a national master plan. On the other side the development of freight centers has been delayed by the lack of terrain required and the reservations against cooperation common amongst logistics organisations.

Unfortunately also reservations against the application of $O R$ techniques are widely spread, though freight centeres requiring an investment of up to a billion DM or even more would offer plenty of opportunities for the implementation of planning and optimization techniques.

The paper will give a survey on the freight center concept and its present implementation, incl. an outline of related OR problems. 